\title{
Characterization of environmental and energy performance of an average social dwelling in a tropical region of Colombia
}

\author{
J. Cárdenas, G. Osma, J. Gutierrez, A. Merchan \& G. Ordóñez \\ Industrial University of Santander, Colombia
}

\begin{abstract}
This work shows the characterization of the conditions of indoor environment and energy behavior of a type of social dwelling of 46 square meters, which will be replicated in several projects in Bucaramanga (Colombia). This city is located $7.1^{\circ}$ north latitude and $71.3^{\circ}$ west longitude to 960 masl. This characterization is made from simulations of a virtual model made in DesignBuilder. The validation of the model was made from measurements such as of air temperature, humidity, daylighting and energy consumption. The four points of the compass were considered in the energy simulations due to the fact that this type of dwelling was built for several orientations in the first project. The simulations were done for daily, monthly and annual periods. The results indicate that the dwelling has high values of thermal gains by occupation and heat that enters through the glazing. The indoor temperature varies between $23^{\circ} \mathrm{C}$ and $31^{\circ} \mathrm{C}$, although that depends on the orientation of the dwelling. The west orientation is the best option because it reduces the annual time that the indoor temperature is above $26^{\circ} \mathrm{C}$. With respect to relative humidity, the variation is between $55 \%$ and $81 \%$ which are common values for natural ventilated inner spaces in this city. However, these mixed conditions cause thermal discomfort for users for most part of suntime (6 a.m. to 6 p.m.) all year. In contrast with that, the daylight level is satisfactory for most inner space between 8 a.m. and 4 p.m. The electrical energy consumption can vary between $1200 \mathrm{kWh}$ and $2400 \mathrm{kWh}$ per year. Finally, an analysis in detail for some inner spaces is presented in the document.
\end{abstract}

Keywords: energy building simulation, DesignBuilder, tropical weather, dwelling. 


\section{Introduction}

Buildings consume about $40 \%$ of the world total energy (Nejat et al. [1]). This consumption tends to rise due to growth factors such as population, the demand of services to satisfy the needs of comfort and the time of use thereof (Pérez et al. [2]).

In Colombia, according to statistics from the International Energy Agency (IEA) for 2012, the building sector claimed approximately $65 \%$ of the total final consumption in the country, where the residential subsector accounted for two thirds of this consumption (IEA [3]). Therefore, the Government of Colombia has promoted energy savings through strategies of rational and efficient use of energy. However, tropical climatic conditions of the country, such as high temperature and relative humidity present in several of its major cities, have conditioned the energy savings in buildings and the comfort of its occupants (Kwong et al. [4]).

This is closely related to the boom in housing construction in Colombia, where social dwellings accounted for $17.5 \%$ in the fourth quarter of 2014 ; this figure being 10\% for the Metropolitan Area of Bucaramanga (DANE [5]).

Currently, there are no studies on energy and environmental behavior of this type of new building, and its impacts, which could be significant given its representativeness. Additionally, there is interest in knowing the quality of life offered with this type of social solutions to poor families.

Given this, an analysis of the energy performance and comfort of social dwellings located in the city of Bucaramanga is carried out through simulations in DesignBuilder.

Initially, the virtual model from measurements of different variables taken in March 2014 was created and validated. Later, energy simulations of the energy performance and thermal comfort were carried out.

The simulation results show thermal discomfort conditions throughout the year, mainly due to the influence of significant internal heat gains related to external glazing and occupation.

On the other hand, energy consumption is conditioned mainly by the use of appliances and lighting. In relation to visual comfort, it is seen that there is a significant daylighting availability, which is consistent with the guidelines of RETILAP (Colombian regulation) regarding the use of this resource.

\section{Methodology}

This section describes the steps followed to carry out the analysis of the energy performance and thermal comfort of social dwellings. Initially, the description of the housing and the creation of virtual model in DesignBuilder is done; later, the validation process of the virtual model and plan addresses simulations are shown.

\subsection{Selected dwelling}

The dwelling subject of this study is located in the city of Bucaramanga, which is located at $7.13^{\circ} \mathrm{N}$ latitude and $73.13^{\circ} \mathrm{W}$ longitude, at a height above sea level of $969 \mathrm{~m}$, near Chicamocha river basin. 
The selection was made considering the construction status of various projects of social dwellings in Bucaramanga, according to information provided by the Institute of Social Dwelling of Bucaramanga (INVISBU), for its acronym in Spanish (governmental entity).

This house is part of a project of 116 households with two floors, whose total area amounts to 45.9 meters (as shown in Figure 1). The living -dining room kitchen, bathroom and patio clothes (uncovered area) are on the first floor; while two bedrooms and a bathroom are on the second floor.

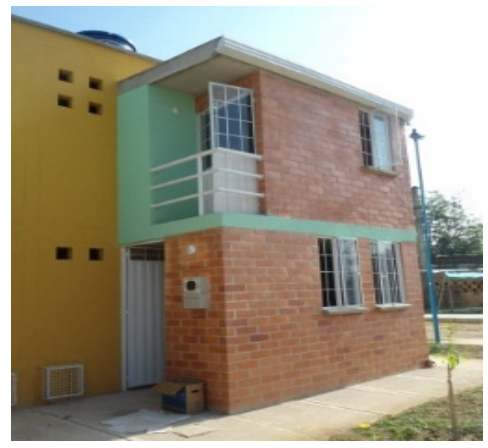

Figure 1: Front view housing studied, Urbanization Paseo La Feria (Stage IV).

The climate of the location of the house is warm-dry and is influenced by an average solar radiation of $4.9 \mathrm{kWh} / \mathrm{m}^{2} /$ day for most of the year. The ambient temperature varies between $24^{\circ} \mathrm{C}$ and $32^{\circ} \mathrm{C}$ and mean annual precipitation levels are close to $1,279 \mathrm{~mm}$.

\subsection{Virtual model of dwelling}

The virtual model housing was generated in the energy simulation tool called DesignBuilder based on the geometrical model building and inclusion of the constructional and operational data model.

\subsubsection{Geometric modeling}

The geometrical model of the dwelling was created from architectural plans, these were imported to DesignBuilder in DXF format for use as guides in the delineation of the outer walls of the building.

Subsequently, openings and interior divisions were made, and heat zones were defined with these, which correspond to each of the spaces of the dwelling. The virtual model obtained is shown in Figure 2. The adjacent buildings to dwelling also were modeled in order to consider shading effects and obstruction. 


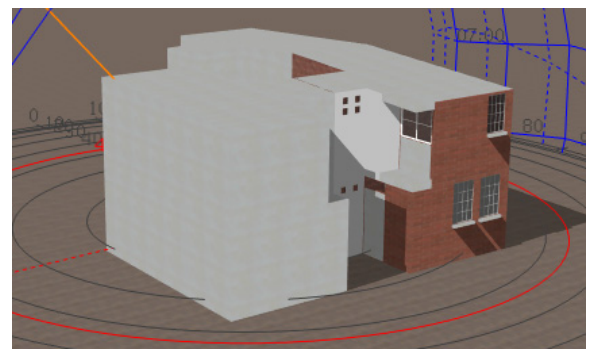

Figure 2: Geometric model of dwelling under study generated DesignBuilder.

\subsubsection{Construction and operational data}

Later to geometric modeling, the including of data was performed according to five categories: activity, construction, openings, lighting and HVAC systems.

Activity category describes the use of areas, including occupation as defined for 5 people. Other information required under this category are shown in Table 1.

Table 1: Data category of activity.

\begin{tabular}{|c|c|}
\hline Parameter & Assigned value \\
\hline Annual holidays & 21 \\
\hline Metabolic factor & 0.9 \\
\hline Summer clothing [Clo] & 0.5 \\
\hline Winter clothing [Clo] & 1 \\
\hline Fresh air per person [1/s-person] & 10 \\
\hline Minimum level of illuminance [Lux] & 200 \\
\hline
\end{tabular}

The materials and thicknesses of the layers comprise the elements of the envelope of the building are part of the construction category, in these two types of exterior walls were defined as brick wall type H15 covered with mortar and brick wall multiperforated. The interior walls are brick type H10, in the same way as the inner layer between the flat plate and the roof; additionally these elements consist of two outer layers of concrete with thickness of three centimeters. The ground floor consists of a layer of concrete $10 \mathrm{~cm}$ thick.

The characteristics and operation of openings are also defined. For dwelling four windows of equal dimensions were established, with frame $2 \mathrm{~cm}$ thick and clear glass $3 \mathrm{~mm}$. The opening area of the windows was set to $50 \%$ of glass area. The luminaries of the dwelling were defined as compact fluorescents in the lighting category. In the category of remaining data (HVAC), natural ventilation was set up as active considering that are no artificial air conditioning systems.

\subsection{Validation of the virtual model}

In order to demonstrate the reliability of the virtual model, a validation process was carried out through comparison of measured variables microclimatic simulation and preliminary results. 


\subsubsection{Measurements of environmental variables}

The microclimatic variables that were monitored are: air temperature, relative humidity and daylighting. These measurements were carried out during March 2014, between 8:00 am and 5:00 pm. As measuring instruments are used Thermohygrometer and Light Meter.

The data collection was performed on an hourly basis considering doors and windows closed (stage A) and open doors and windows (stage B), this in order to evaluate the influence of changing some parameters on the behavior of the variables studied. The indoor temperature and relative humidity were measured at 1.2 meters from the ground, while the level of natural light was measured at a height of 0.7 meters. The measuring points correspond to the letters shown in Figure 3. Spaces larger area, such as living - dining room - kitchen, bedroom patio and bedroom balcony, having more than one measuring point.
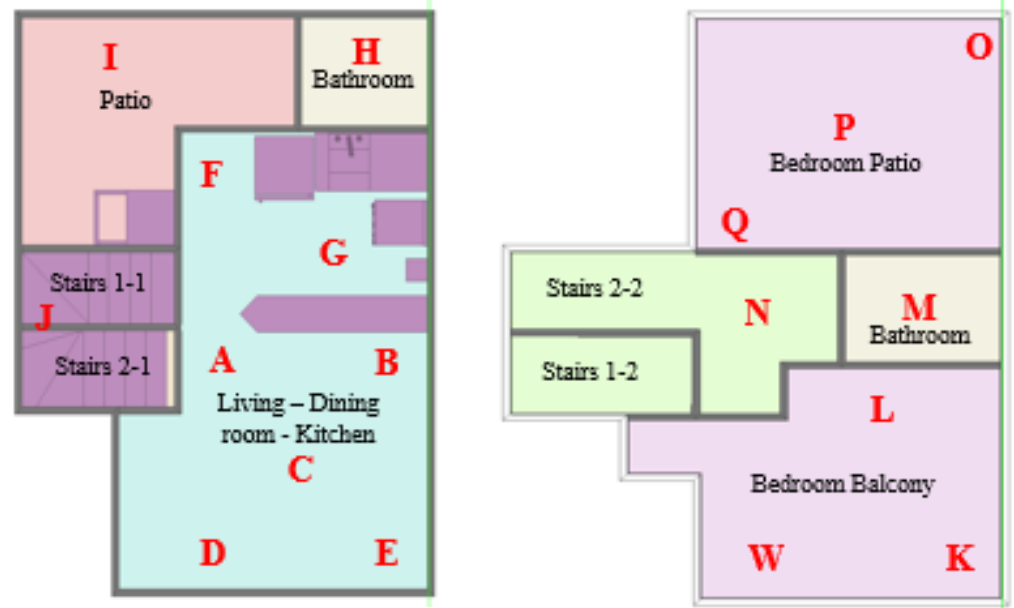

Figure 3: Location of measurement points of environmental variables.

\subsubsection{Comparison between measured and simulated values}

Figure 4 shows the comparison between measured and simulated values of air temperature in the living-dining room - kitchen zone for a typical day in March, when the house is oriented towards south and is with doors and windows closed (stage A). The similarity between the measured and simulated is significant; for which, the average difference is only $1.56 \%$.

The reliability of the virtual model was evaluated considering the maximum percentage error and the mean square error between measured and simulated values. The spaces selected to conduct the comparison were living-dining room - kitchen, patio, and the rooms on the top floor, due to the representativeness of their areas. Table 2 presents the deficiencies noted for the air temperature and relative humidity. 


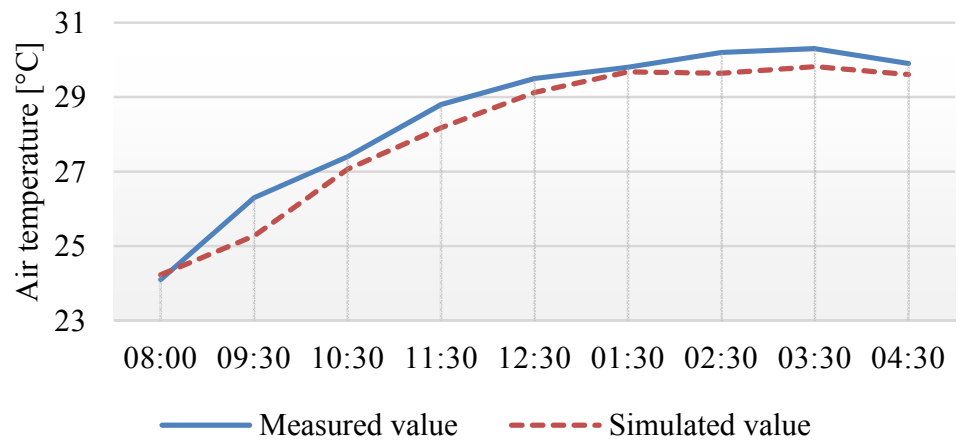

Figure 4: Comparison between measured and simulated air temperature in the zone living - dining room - kitchen for the 27 March, taking into account the fact that windows and doors are closed.

Table 2: $\quad$ Maximum error percentage and mean square of the air temperature and relative humidity for selected areas.

\begin{tabular}{|c|c|c|c|c|c|}
\hline \multirow{2}{*}{ Zone } & \multirow{2}{*}{ Stage } & \multicolumn{2}{|c|}{ Air temperature } & \multicolumn{2}{c|}{ Relative humidity } \\
\cline { 3 - 6 } & & $\begin{array}{c}\text { Maximum } \\
\text { error [\%] }\end{array}$ & MSE [ $\left.{ }^{\circ} \mathrm{C}\right]$ & $\begin{array}{c}\text { Maximum } \\
\text { error [\%] }\end{array}$ & MSE [\%] \\
\hline $\begin{array}{c}\text { Living -dining } \\
\text { room - kitchen }\end{array}$ & $\mathrm{A}$ & 3.88 & 0.7 & 17.19 & 2.02 \\
\cline { 2 - 6 } & $\mathrm{B}$ & 9.27 & 0.55 & 38.33 & 3.38 \\
\hline \multirow{2}{*}{ Patio } & $\mathrm{A}$ & 8.60 & 0.4 & 18.88 & 2.07 \\
\cline { 2 - 6 } & $\mathrm{B}$ & 4.82 & 0.21 & 17.21 & 2.02 \\
\hline \multirow{2}{*}{$\begin{array}{c}\text { Bedroom } \\
\text { Balcony }\end{array}$} & $\mathrm{A}$ & 13.30 & 0.82 & 24.49 & 2.93 \\
\cline { 2 - 6 } & $\mathrm{B}$ & 11.79 & 0.67 & 29.46 & 3.30 \\
\hline \multirow{2}{*}{ Bedroom Patio } & $\mathrm{A}$ & 7.59 & 0.36 & 18.93 & 2.08 \\
\cline { 2 - 6 } & $\mathrm{B}$ & 6.92 & 0.29 & 19.89 & 1.98 \\
\hline
\end{tabular}

According to the MSE, areas with simulated temperature of the air near the measured values are bedroom patio and patio with $0.21^{\circ} \mathrm{C}$ and $0.29^{\circ} \mathrm{C}$, respectively. In contrast, the largest difference occurs in the bedroom balcony with $0.82^{\circ} \mathrm{C}$. In the case of relative humidity, minor errors occurred in the bedroom patio and patio.

Considering the scenarios analyzed, the lowest MSE in air temperature occurs with doors and windows open for most of the spaces. In the case of the relative humidity, there is no distinction for the two cases; moreover, the difference is primarily between $2 \%$ and $3 \%$.

Additionally, the simulated annual value of energy consumption and the average value measured by the local power company were compared, an approximate $18 \%$ difference was found between these values. Which may be due to the configuration of the use regime appliances, a complicated aspect of modeling in energy simulation tools. From the above, the virtual model of housing 
is considered appropriate for use in the analysis of indoor environment and energy performance; the central objective of this research.

\subsection{Simulations plan}

Simulations for the analysis of the energy performance and thermal comfort of the dwelling are grouped in simulations of validation, daily simulations and monthly - annually simulations. Given that, the dwellings of the project have different orientations, simulations were performed considering four different orientations for the facade of the dwelling: North, South, East and West. In total, twelve simulations were performed, of which nine are energy simulations and three are simulations of Daylighting. The simulations plan is shown in Table 3.

Table 3: Simulations plan.

\begin{tabular}{|c|c|c|c|c|c|}
\hline $\begin{array}{l}\text { Simulations } \\
\text { group }\end{array}$ & Type & \multicolumn{2}{|c|}{$\begin{array}{l}\text { Quantity/ } \\
\text { Stage }\end{array}$} & $\begin{array}{l}\text { Simulation } \\
\text { interval }\end{array}$ & Orientation \\
\hline \multirow{5}{*}{$\begin{array}{l}\text { Validation } \\
\text { simulations }\end{array}$} & \multirow{2}{*}{ Energy } & 1 & A & \multirow{2}{*}{ Journal (hours) } & \multirow{5}{*}{ South } \\
\hline & & 1 & $\mathrm{~B}$ & & \\
\hline & \multirow{3}{*}{ Daylighting } & 1 & \multirow{3}{*}{ B } & 9:00 a.m. & \\
\hline & & 1 & & $12: 00 \mathrm{~m}$. & \\
\hline & & 1 & & 5:00 p.m. & \\
\hline \multirow{3}{*}{$\begin{array}{c}\text { Daily } \\
\text { simulations }\end{array}$} & \multirow{3}{*}{ Energy } & 1 & \multirow{3}{*}{ B } & Journal (hours) & North \\
\hline & & 1 & & Journal (hours) & East \\
\hline & & 1 & & Journal (hours) & West \\
\hline \multirow{4}{*}{$\begin{array}{l}\text { Monthly - } \\
\text { annually } \\
\text { simulations }\end{array}$} & \multirow{4}{*}{ Energy } & 1 & \multirow{4}{*}{ B } & \multirow{4}{*}{$\begin{array}{l}\text { Monthly and } \\
\text { annual }\end{array}$} & South \\
\hline & & 1 & & & North \\
\hline & & 1 & & & East \\
\hline & & 1 & & & West \\
\hline
\end{tabular}

\section{Analysis of results}

The analysis of topics such as thermal comfort, indoor heat gains, energy consumption and visual comfort were carried out in order to describe the energy behavior and quality of inner of dwelling considered.

\subsection{Analysis of the indoor environment}

The daily results of air temperature and relative humidity were considered in the analysis of the indoor environment. Preliminarily, the analysis of air temperature and relative humidity in the living-dining room - kitchen (the space largest in the dwelling) showed that the lowest air temperature is obtained under the orientation South and East. This is due to the low incidence of solar radiation on the external walls. 
Conversely, the highest temperatures occur in the West orientation, where the sun incises all day on the largest wall, and in the afternoon on the walls of the façade. This causes an increase in temperature inside, as shown in Figure 5.

The differences between the behaviors of air temperature for each orientation are more noticeable in the period between 9:00 am and 8:00 pm. The maximum temperatures for all orientations were presented between 12:00 m. and 3:00 p.m.
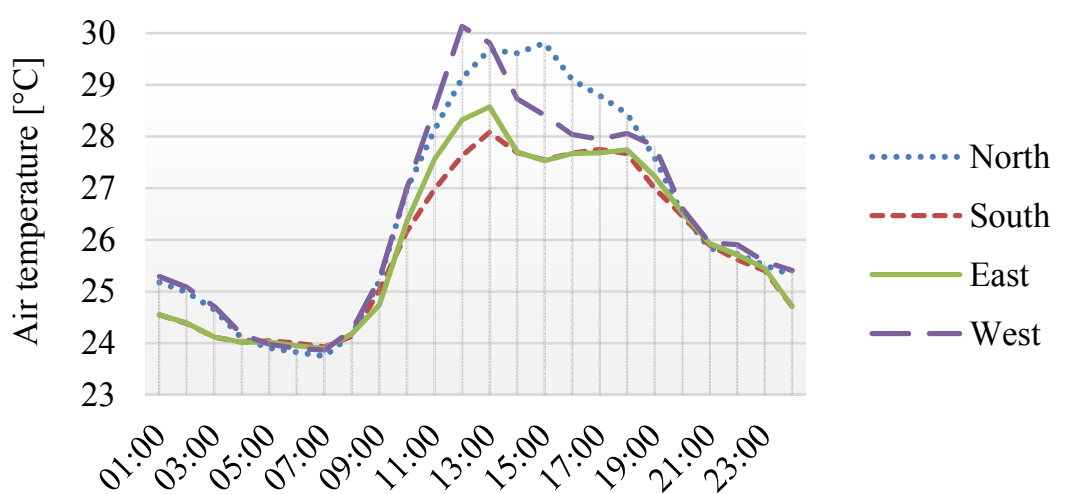

Figure 5: Average air temperature for the living-dining room - kitchen in the four directions on 27 March.

A monthly analysis of the behavior of air temperature and relative humidity in each area was realized. This identified the most adverse environmental conditions for spaces on the upper floor of the dwelling because of the internal heating produced by the incidence of solar radiation on the roof and much of the walls. In general, the upper floor has an average annual temperature of $26^{\circ} \mathrm{C}$, which is $0.6^{\circ} \mathrm{C}$ higher than the value in the ground floor.

The bedroom patio area has the most unfavorable conditions for all orientations, in this zone the annual temperatures are above $26.2^{\circ} \mathrm{C}$.

With respect to the relative humidity, the lowest values occur for West orientation. This may be due to the way the solar radiation incident on the walls in each orientations. As a result of the monthly analysis, an average annual relative humidity of $72.8 \%$ in the spaces upper floor was found, worth two percentage points lower than on the ground floor.

An overall assessment of environmental conditions in dwelling, determined that the West, East and South orientations significantly favor the environment inside of the dwelling compared to North orientation. In addition the West orientation is highlighted in the indoor temperature behavior shown in Figure 6. This is because under the West orientation heat losses occur through intentional air flow (natural ventilation) and unintentional air flows (infiltration). 

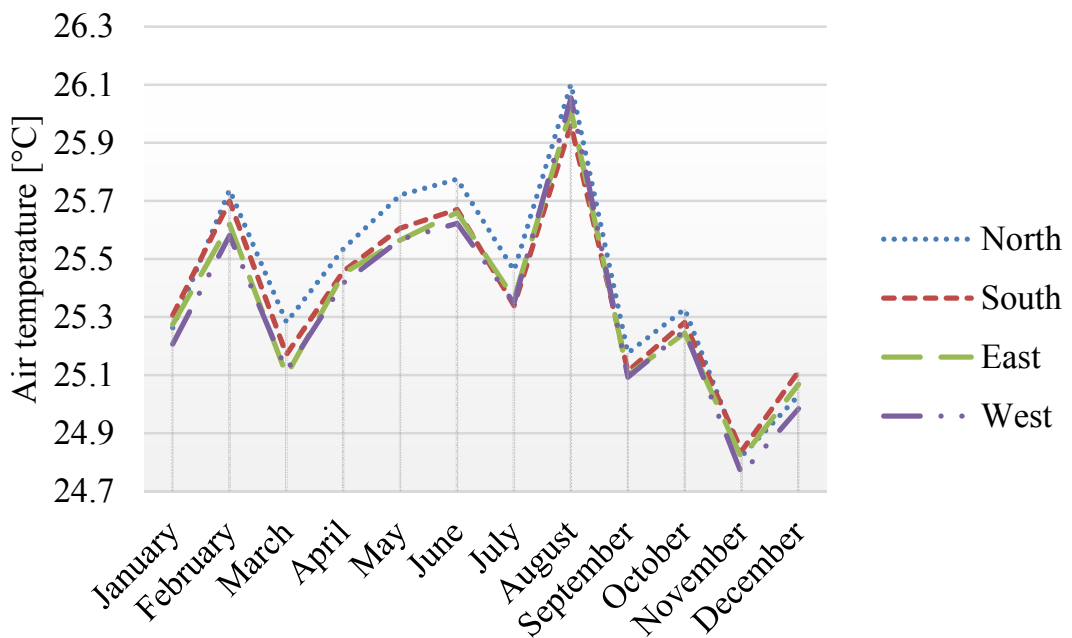

Figure 6: Average monthly air temperature for dwelling, considering the four orientations.

\subsection{Internal heat gains}

The most significant heat sources within spaces the dwelling are heat entering windows and associated to the occupation. Figure 7 shows the breakdown of internal heat gains to the actual orientation (South) of the building.

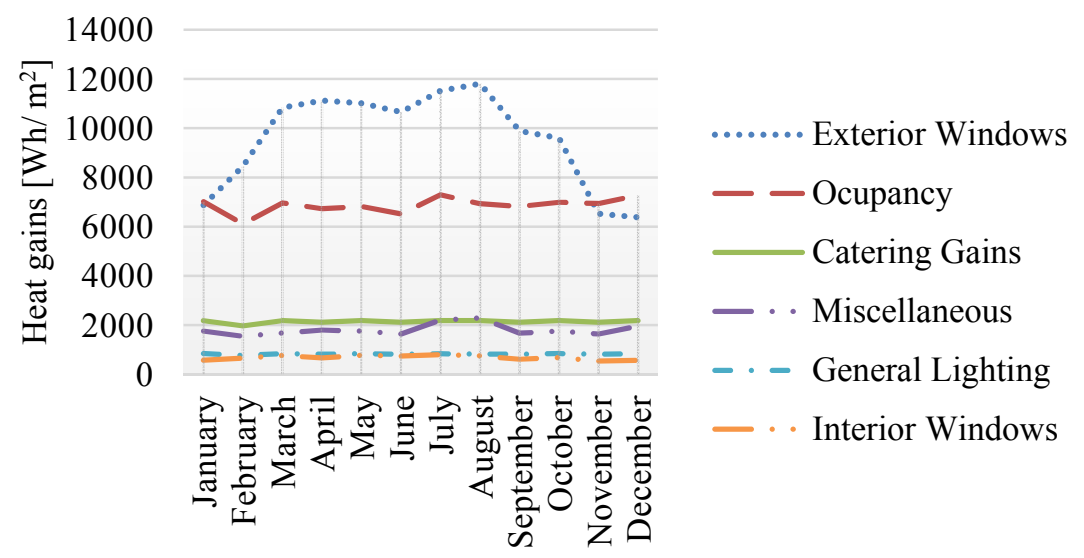

Figure 7: Average monthly internal heat gains for housing under the south orientation.

According to Figure 7, the thermal gains of exterior windows and occupation represent $43.4 \%$ and $31.8 \%$, respectively, of total internal heat gains. 


\subsection{Energy consumption}

The simulated annual energy consumption to $1980 \mathrm{kWh}$ per year, where $90 \%$ is caused by household appliances consumption, the remaining $10 \%$ is due to artificial lighting. By comparing this value with the average value measured by the local energy company, the simulated value is $360 \mathrm{kWh}$ per year higher than the value measured. This difference may be due to the configuration of the regime of use of appliances, which is a complicated aspect of modeling in energy simulation tools. Environmentally, the energy consumption associated with the building causes about $1,357 \mathrm{~kg}$ of $\mathrm{CO}_{2}$ annually.

\subsection{Analysis of visual comfort and thermal}

The evaluation of the thermal comfort in housing was made taking into account the procedures set forth in the CIBSE reference guide A / ISO 7730. According to this, the thermal comfort of spaces in a dwelling is subject to annual percentage of hours where the air temperature is below $26^{\circ} \mathrm{C}$ respectively. The reference percentage applicable annual time is $1 \%$ for both types of spaces. According to the results, each area has a percentage top to $26^{\circ} \mathrm{C}$. Therefore, the dwelling presents conditions of discomfort in each area.

DesignBuilder evaluates the level of thermal comfort through comfort indices such as: VMP Fanger, the VMP TE from Pierce, Pierce VMP TEE, and VST of the University of Kansas. Figure 8 shows the application of these indices for this study. Interpreting thermal comfort indices takes into account the thermal sensation scale described in Table 4.

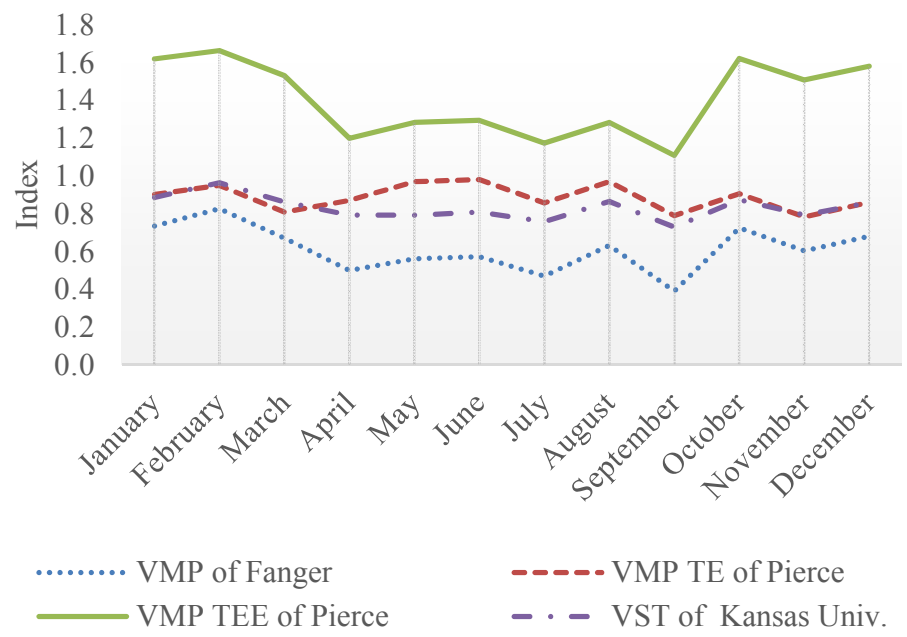

Figure 8: Thermal comfort indices estimated for the actual orientation of the dwelling. 
Table 4: Thermal sensation scale used to interpret the thermal comfort indices.

\begin{tabular}{|c|l|}
\hline Index & \multicolumn{1}{|c|}{ Meaning } \\
\hline-3 & Very cold \\
\hline-2 & Cold \\
\hline-1 & Slightly cold \\
\hline 0 & Neutral (comfortable) \\
\hline+1 & Slightly hot \\
\hline+2 & Hot \\
\hline+3 & Too warm \\
\hline
\end{tabular}

According to Figure 8, the PMV Fanger indices, VMP TE Pierce, and VST University of Kansas suggests a wind chill near a slightly warm environment throughout the year. For the case of VMP TEE index Pierce, the discomfort conditions approach a hot environment.

Regarding the visual comfort, favorable conditions of natural lighting were found in every spaces of the house between 9:00 am and 5:00 pm; average levels of lighting present in the space are in keeping with local lighting regulations.

\section{Conclusion}

Given the significant increase in the construction of social dwelling in Colombia in recent years, and considering that such initiative can be maintained for the next decade, it is important to conduct studies that examine the interior comfort and energy performance of dwelling, in order to carry out design improvements that provide higher quality life to low-income families.

DesignBuilder facilitated significantly the development of dwelling analysis, including orientation study in detail. Regarding simulations of air temperature and relative humidity, the results indicate that the environmental conditions are unfavorable throughout the year, which is evident in the high values of these microclimatic variables. In general, the air temperature is between $23^{\circ} \mathrm{C}$ and $31^{\circ} \mathrm{C}$ with $26^{\circ} \mathrm{C}$ average annual value. Furthermore, the variation of the relative humidity is between $55 \%$ and $81 \%$.

From a zonal analysis, a significant disadvantage for areas upstairs was evident, as is the case Bedroom Patio, the values of air temperature reached to almost $27^{\circ} \mathrm{C}$ in all orientations. The most relevant source of this discomfort was found to internal heat gains related to external windows and occupation. This is confirmed from the evaluation of the thermal comfort based on CIBSE criteria and indices of thermal comfort, these indicate that users of dwelling experienced conditions of thermal discomfort throughout the year and a wind chill ranging from slightly warm to hot. The opposite happens with the visual comfort provided by natural light, which satisfies the applicable regulations, according to the comparing means Daylighting simulations required luminance values in each type of space.

An annual analysis of the behavior of temperature and relative humidity indicated as favorable orientations towards the west, the east and south. However, the most favorable environmental conditions present when the dwelling is oriented 
westward. This occurs mainly by action of natural ventilation and external infiltrations.

According to the energy simulations, housing presents an approximate consumption of $1980 \mathrm{kWh} /$ year. The accuracy of this value compared to measured values are affected by the configuration tool is made in the use of electrical appliances and home systems.

\section{References}

[1] Nejat, P., Jomehzadeh, F., Taheri,M., Gohari, M. \& Majid, M., A global review of energy consumption, $\mathrm{CO} 2$ emissions and policy in the residential sector (with an overview of the top ten CO2 emitting countries), Renew. Sustain. Energy Rev., vol. 43, pp. 843-862, Mar. 2015.

[2] Pérez, L., Ortiz, J. \& and Pout, C. A review on buildings energy consumption information, Energy Build., vol. 40, no. 3, pp. 394-398, Jan. 2008.

[3] International Energy Agency (IEA), Official Web Site, Paris, France, http://www.iea.org

[4] Kwong, Q., Adam, N. \& Sahari, B., Thermal comfort assessment and potential for energy efficiency enhancement in modern tropical buildings: A review, Energy Build., vol. 68, pp. 547-557, Jan. 2014.

[5] Boletín técnico Vivienda VIS y No VIS, Departamento Administrativo Nacional de Estadística (DANE) 2015. 